\title{
Annona muricata L. extracts decrease melanogenesis in B16F10 mouse melanoma cells
}

Dahye Joo', Seonghee Jeong ${ }^{1}$, Hyun Kyung Lee', Shang Hun Shin ${ }^{1}$, Seong Jin Choi ${ }^{1}$, Karam Kim ${ }^{1}$, In-Sook An ${ }^{1}$, Kyung-Yun Kim², Jung-Eun $\mathrm{Ku}^{3}$, Sun-Hee Jeong ${ }^{4}$ and Hwa Jun Cha ${ }^{5,6^{*}}$

\begin{abstract}
Background: Annona muricata (A. muricata) L. (also known as graviola) contains various antioxidants that have beneficial effects on headaches, hypertension, coughs and asthma. A. muricata L. also has various other physiological effects, such as antispasmodic effects for the treatment of heart conditions, and sedative and nervine effects. In the present study, the effect of A. muricata L. extracts on melanogenesis was investigated and the ensuing inhibitory mechanisms were determined.

Methods: The inhibitory effects of A. muricata L. extracts on melanogenesis were initially investigated by measuring melanin contents. Subsequently, the ensuing mechanisms were characterized by determining changes in the activity of tyrosinase, which is the rate-limiting step of melanogenesis. Finally, mRNA and protein expression levels of tyrosinase and the melanogenesis-associated transcription factor (MITF) were determined.

Results: Decreased melanin contents after treatments with A. muricata L. extracts suggested skin-whitening effects, and these changes were reflected by decreased tyrosinase activities. In addition, tyrosinase mRNA and protein expression levels were regulated by A. muricata L. extracts. MITF is a known key transcription factor of tyrosinase and was transcriptionally regulated by A. muricata L. extracts. Specifically, MITF mRNA expression levels were decreased in the presence of $A$. muricata $\mathrm{L}$. extracts. Taken together, the melanogenesis-moderating effects of $A$. muricata $\mathrm{L}$. extracts follow suppression of MITF mRNA expression and subsequent transactivation of tyrosinase.

Conclusions: The results of the present study confirm the skin-whitening effects of A. muricata $\mathrm{L}$. and characterize the related molecular mechanisms. These data indicate that A. muricata $L$. has high potential as an ingredient of skin-whitening cosmetics.
\end{abstract}

Keywords: Annona muricata, Melanogenesis, B16F10, MITF, Tyrosinase

\section{Background}

Annona muricata (A. muricata) $\mathrm{L}$. is an evergreen tree of about 5-6 $\mathrm{m}$ in height that is best known as graviola and is prevalent in tropical regions of South America and North America, especially in the Amazon. The sweet oval fruit is prickly and has white flesh inside a dark green or yellow green rind. Bark, leaves, roots and seeds of graviola have been used as traditional medicines, and parts

\footnotetext{
* Correspondence: hjcha@osan.ac.kr

${ }^{5}$ Department of Skin Care and Beauty, Osan University, Osan-si, Gyeonggi-do 18119, Republic of Korea

${ }^{6}$ Department of Skin Care and Cosmetics, Osan University, 45 Cheonghak-ro, Osan-si, Gyeonggi-do 18119, Republic of Korea

Full list of author information is available at the end of the article
}

of the plant have differing effects and methods of utilization (Asare et al. 2015). Graviola has excellent antioxidant effects due to the abundance of polyphenols and is effective against headaches, hypertension, coughs and asthma. In recent applications, graviola has been used as an antispasmodic agent for the treatment of heart conditions, as well as a sedative and nervine agent (Lans 2006; Baskar et al. 2007). In addition, active components of the leaves and seeds are known to have cytotoxic effects against cancer cells (Baskar et al. 2007).

Over the past century, environmental pollution from rapid industrialization led to depletion of the ozone layer, and the increased ultraviolet irradiation ( $\mathrm{Yu}$ et al. 2005) 
has known effects on the colour of human skin. The natural skin pigment melanin is the fundamental internal factor that determines human skin colour (Jeong et al. 2005). Excessive melanin synthesis due to sun exposure is known to cause melasma, freckles and spots and promotes skin aging and may be involved in dermal carcinogenesis (Chen et al. 1991; Urabe et al. 1994). The rate-limiting step in the biosynthesis of melanin (Hearing and Tsukamoto 1991) involves the initial hydroxylation of tyrosine by tyrosinase, which produces 3,4-dihydroxyphenylalanine (DOPA) (Jimenez-Cervantes et al. 1994). Recently, studies of melanogenesis have been conducted following inhibition of tyrosinase, microphthalmiaassociated transcription factor (MITF) and the tyrosinaserelated proteins 1 (TRP-1) and 2 (TRP-2) (Parvez et al. 2006). Melanin synthesis is sensitive to various intracellular signal pathways, including (1) the cyclic adenosine monophosphate/protein kinase A (cAMP/PKA) pathway; (2) the cyclic guanosine monophosphate pathway, which is based on nitric oxide; (3) the protein kinase $C$ pathway; and (4) the p38 MAP kinase pathway. Among these, the cAMP/PKA pathway is central to melanogenesis and follows induction of MITF expression by the cAMP response element binding protein (CREB) after exposure to UV (Busca and Ballotti 2000; Sassone 1998). As a central melanogenesis transcription factor, MITF induces tyrosinase, TRP-1 and TRP-2 transcription (Busca and Ballotti 2000; Saha et al. 2006). Arbutin, which is the most frequently used skin-whitening agent, is an inhibitor that competes with l-tyrosine. Moreover, arbutin and ascorbic acid chelate copper atoms from the active site of tyrosinase and inhibit the conversion of tyrosine to DOPA and DOPA to DOPA quinone (Maeda and Fukuda 1996; Battaini et al. 2000). However, limited quantities of arbutin are currently used in medicines and cosmetics, because of issues involving skin safety and formulation stability (Chun et al. 2002; Curto et al. 1999). Therefore, further studies of natural skin-whitening agents are warranted. Herein, we verified the skin-whitening effects of $A$. muricata $\mathrm{L}$. and characterized the ensuing intracellular signalling mechanisms.

\section{Methods}

\section{Cells and cell culture}

B16F10 cells were cultured in Dulbecco's modified Eagle's medium (DMEM; HyClone, USA) containing foetal bovine serum (FBS; HyClone), which was purchased from Gibco (USA), and the antibiotics penicillin and streptomycin, which were purchased from Invitrogen ${ }^{\text {Tw }}$ (USA). HaCaT cells were cultured at $37{ }^{\circ} \mathrm{C}$ in an incubator containing $5 \%$ $\mathrm{CO}_{2}$ at $100 \%$ relative humidity.

\section{Preparation of $A$. muricata $L$. extracts}

Dried $A$. muricata L. tissues were pulverized and extracted in 10 volumes of $70 \%$ ethanol for $1 \mathrm{~h}$ in a sonicator. The mixture was then filtered with Whatman No. 2 filter paper, and the resulting filtrate was freeze-dried using a freezedryer (PVTFD-10R; IlShinBioBase, Dongducheon, Korea) and was stored at $-20^{\circ} \mathrm{C}$ until analysis.

\section{Cytotoxicity assays}

Cytotoxic activities of $A$. muricata L. extracts were determined using 3-[4,5-dimethylthiazol-2-yl]-2,5-diphenyltetrazolium bromide (MTT) assays as described previously (Mosmann 1983). Briefly, B16F10 cells were seeded into 96-well plates at $5 \times 10^{3}$ cells/well and then cultured for $24 \mathrm{~h}$. Culture solutions were then replaced with serum-free DMEM, and samples were treated with A. muricata $\mathrm{L}$. extracts at various concentrations for $48 \mathrm{~h}$. The cells were then washed with phosphate-buffered saline (PBS; Thermo Fisher Scientific, USA), and MTT (Sigma-Aldrich, USA) solution was added to each well and incubated for $1-2 \mathrm{~h}$ at $37{ }^{\circ} \mathrm{C}$. After removing the MTT solution, $200 \mu \mathrm{L}$ of DMSO (Sigma-Aldrich, USA) was added to dissolve the formed formazan crystals and absorbance was determined using an ELISA reader at $540 \mathrm{~nm}$.

\section{Measurements of melanin contents}

Melanin contents of cells were determined using the method described by Hosoi et al. (1985) with slight modifications. Briefly, cells were washed with PBS three times and then centrifuged to obtain cell pellets. The pellets were then placed in $200-\mu \mathrm{L}$ aliquots of $1-\mathrm{N} \mathrm{NaOH}$ containing $10 \%$ DMSO and were incubated at $80{ }^{\circ} \mathrm{C}$ for $1 \mathrm{~h}$. Subsequently, absorbance was measured at $405 \mathrm{~nm}$ using the ELISA reader, and total melanin contents were expressed as percentages of the control group.

\section{In vitro tyrosinase activity assays}

Tyrosinase is the rate-limiting enzyme in melanogenesis and catalyses the oxidation of tyrosine to 3,4-dihydroxyphenylalanine (DOPA) and then to DOPA quinone. In previous studies of skin-whitening activities, melanin absorbance was measured before and after oxidation reactions to investigate the capacity of samples to inhibit tyrosinase activity (Kwon et al. 2014). Herein, 1.7-mM l-tyrosine was completely dissolved in 10-mM sodium phosphate buffer ( $\mathrm{pH} 6.8$ ). Subsequently, $5-\mu \mathrm{L}$ aliquots of $A$. muricata $\mathrm{L}$. extracts at various concentrations of up to $0.3 \mathrm{mg} / \mathrm{mL}$ were added to $450-\mu \mathrm{L}$ aliquots of l-tyrosine. Mushroom tyrosinase $(250 \mathrm{U} / \mathrm{mL} ; 50 \mu \mathrm{L})$ was then added, mixed and incubated at $37^{\circ} \mathrm{C}$ for $60 \mathrm{~min}$, and absorbance was measured at $475 \mathrm{~nm}$.

\section{Tyrosinase activity assays}

Tyrosinase activities were measured using the methods described by Choi et al. (1998). Briefly, treated cells were lysed in $100-\mu \mathrm{L}$ aliquots of cell lysis solution and then centrifuged. Subsequently, $50-\mu \mathrm{L}$ aliquots of the resulting supernatants were added to $450-\mu \mathrm{L}$ solutions of $1.7-\mathrm{mM}$ 
-tyrosine and 0.1-M PBS and incubated at $37{ }^{\circ} \mathrm{C}$ for 15 min prior to measurements of absorbance at $490 \mathrm{~nm}$ using an ELISA reader. Enzyme activities were expressed as percentages of those in the control group. Tyrosinase inhibitory activities of extracts were expressed as percentage absorbance decreases relative to the untreated control group.

\section{qRT-PCR analysis}

B16F10 cells were pretreated with extracts for $3 \mathrm{~h}$ and then incubated with 200-nM $\alpha$-MSH for $48 \mathrm{~h}$. After removing the culture solution, RNA extraction was performed using TRIzol (Invitrogen ${ }^{\mathrm{T} \mathrm{M}}$, USA). RNA contents were then measured by a NanoDrop spectrophotometer (Thermo Scientific, USA), and equal amounts of RNA were used to synthesize cDNA with PrimeScript Reverse Transcriptase (Takara, Japan). Subsequently, gene expression was determined using qRT-PCR with the HOT FIREPol EvaGreen PCR Mix Plus (Solis BioDyne) and the primers presented in a StepOnePlus Real-Time PCR System (Applied Biosystems, Thermo Fisher Scientific, USA). PCR was performed with denaturation at initial denaturation at $94{ }^{\circ} \mathrm{C}$ for $3 \mathrm{~min}$, followed by 40 cycles of denaturation $\left(94{ }^{\circ} \mathrm{C}, 30 \mathrm{~s}\right)$, annealing $\left(58{ }^{\circ} \mathrm{C}, 30 \mathrm{~s}\right)$ and polymerization $\left(72{ }^{\circ} \mathrm{C}, 30 \mathrm{~s}\right)$. Data were analysed using the exclusive software program (ver. 2.0.6) provided by Applied Biosystems (USA).

\section{Promoter activity assays}

B16F10 cells were seeded into 60-mm culture dishes and cultured for $24 \mathrm{~h}$ and then transfected with a vector for the expression of the pGL-MITF reporter. Transfected
B16F10 cells were then treated with the extracts for $24 \mathrm{~h}$, and luciferase activities were measured according to the protocol provided by the manufacturer of the luciferase assay system. Inhibitory activities were expressed relative to controls that were treated with $\alpha-\mathrm{MSH}$.

\section{Western blotting analysis}

After cell treatments, culture media were removed and the cells were washed twice in ice-cold PBS ( $\mathrm{pH} 7.4)$ and then incubated on ice for $20 \mathrm{~min}$ in a radioimmunoprecipitation assay buffer (Sigma-Aldrich, USA) containing protease inhibitors (Roche, Germany). Lysates were then centrifuged at $10,000 \mathrm{~g}$ for $15 \mathrm{~min}$ at $4{ }^{\circ} \mathrm{C}$, and protein concentrations of supernatants were measured using the Bradford method. After adjusting protein concentrations of all samples, equal quantities of protein were mixed with $5 \times$ sodium dodecyl sulphate (SDS) sample buffer (SigmaAldrich) and boiled at $100{ }^{\circ} \mathrm{C}$ for $5 \mathrm{~min}$. SDS-protein samples were then electrophoresed on $8-10 \%$ SDS polyacrylamide gels using a Mini-PROTEAN system (Bio-Rad, USA). Protein bands were then transferred to cellulose membranes (GE Healthcare Life Sciences, UK) and blocked in Tris-buffered saline (TBST, pH 8.0) containing $0.1 \%$ Tween-20 and 5\% skim milk at room temperature for $1 \mathrm{~h}$. Membranes were probed with anti-MMP-1 and anti-type-1 procollagen, anti-MMP-3 (Santa Cruz Biotechnology, USA) or anti- $\beta$-actin (Sigma-Aldrich) primary antibodies in blocking solution at $4{ }^{\circ} \mathrm{C}$ for $18 \mathrm{~h}$. Membranes were then washed in TBST and exposed to the following secondary antibodies for $2 \mathrm{~h}$ at room temperature: Horseradish peroxidase-conjugated anti-rabbit IgG and anti-goat IgG (Santa Cruz Biotechnology), anti-mouse IgG
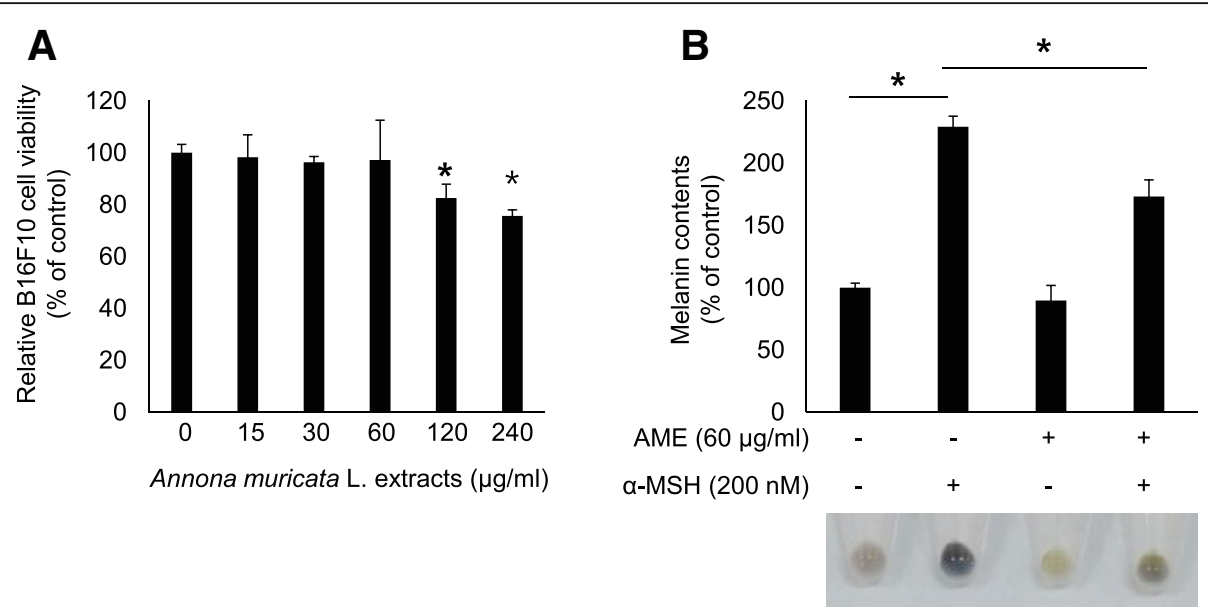

Fig. 1 Effects of A. muricata L. extracts on melanin production and cell viability in B16F10 melanoma cells. a Effects of $A$. muricata extracts on cytotoxicity in B16F10 melanoma cells. MTT assays were used to determine cytotoxic activities and appropriate concentration ranges in B16F10 cells. In these experiments, survival rates were $90 \%$ or higher after treatments with A. muricata L. extracts at $60 \mu \mathrm{g} / \mathrm{mL}$ or less. $\mathbf{b}$ Effects of $A$. muricata extracts on melanin contents in B16F10 melanoma cells; ${ }^{*} p<0.05$. Melanin contents of mouse melanoma cells were determined after treatment with $A$. muricata L. extracts at $60 \mu \mathrm{g} / \mathrm{mL}$. In these experiments, a-MSH-induced melanogenesis was reduced to $24.42 \%$ in cells treated with A. muricata L. extracts compared to those treated with a-MSH only 


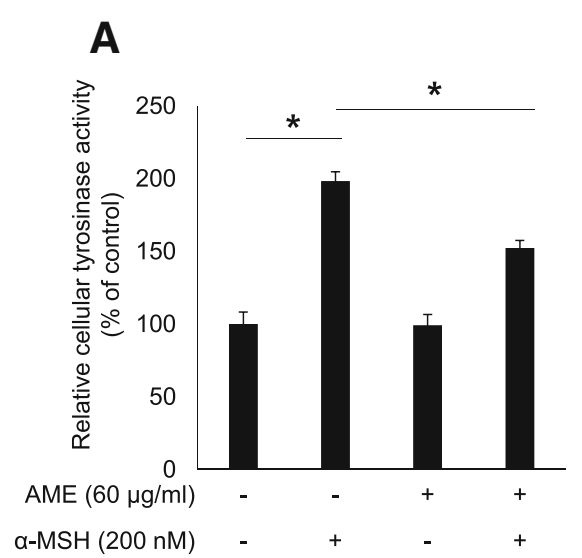

B

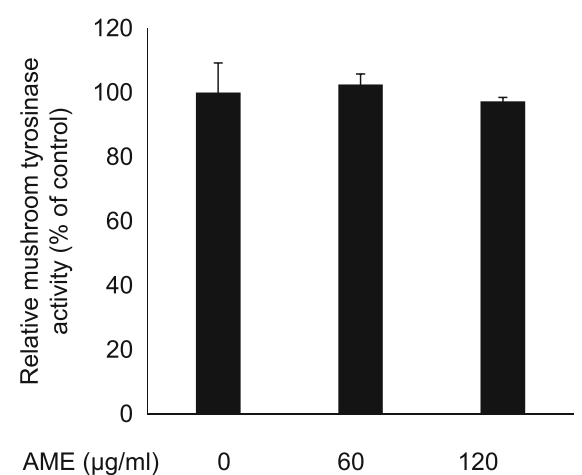

Fig. 2 Effects of A. muricata L. extracts on tyrosinase activities. a Effects of A. muricata L. extracts on cellular tyrosinase activity in B16F10 melanoma cells. A. muricata L. extracts decreased tyrosinase activities to $23.24 \%$ at $60 \mu \mathrm{g} / \mathrm{mL}$. b Effects of $A$. muricata L. extracts on mushroom tyrosinase activity; ${ }^{*} p<0.05$

(Sigma-Aldrich) After washing, ECL solution (Pierce, USA) was sprayed onto the membranes, and bands were identified and quantified using an LAS-3000 Luminescent Image Analyser (Fujifilm, Japan).

\section{Statistical analysis}

Data are presented as means \pm standard deviations, and differences were identified using Student's $t$ test. Differences were considered significant when $p<0.05$.

\section{Results}

\section{Cytotoxicity assays of $A$. muricata L. extracts}

MTT assays were used to determine cytotoxic activities and appropriate concentration ranges in B16F10 cells. In these experiments, survival rates were $90 \%$ or higher after treatments with $A$. muricata L. extracts at $60 \mu \mathrm{g} /$ $\mathrm{mL}$ or less (Fig. 1a). Therefore, subsequent experiments were performed with extracts at $\leq 60 \mu \mathrm{g} / \mathrm{mL}$.
Measurement of skin-whitening effects of $A$. muricata $\mathrm{L}$. extracts

To assess the skin-whitening effects of $A$. muricata L. extracts, melanin contents of mouse melanoma cells were determined after treatment with $A$. muricata $\mathrm{L}$. extracts at $60 \mu \mathrm{g} / \mathrm{mL}$. In these experiments, $\alpha-\mathrm{MSH}$ induced melanogenesis was reduced to $24.42 \%$ in cells treated with $A$. muricata L. extracts compared to those treated with $\alpha-\mathrm{MSH}$ only (Fig. 1b).

Changed tyrosinase activities and expression levels in the presence of $A$. muricata $L$. extracts

A. muricata L. extracts decreased tyrosinase activities to $23.24 \%$ at $60 \mu \mathrm{g} / \mathrm{mL}$ (Fig. 2a). To determine whether $A$. muricata L. extracts inhibit tyrosinase directly (Fig. 2b), we measured changes in the expression of tyrosinase mRNA and protein (Fig. 3) and showed 23.24 and 48.13\% decrease, respectively, following treatment with $A$. muricata L. extracts. These data suggest that
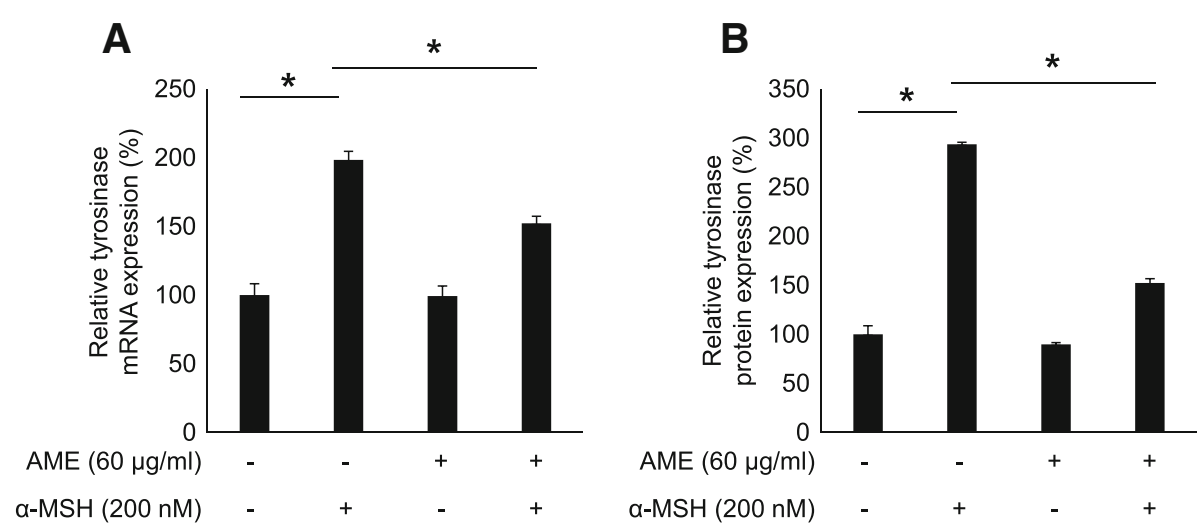

Fig. 3 Effects of $A$. muricata L. extracts on tyrosinase expression levels in B16F10 melanoma cells. a Effects of $A$. muricata L. extracts on tyrosinase mRNA and $\mathbf{b}$ protein expression in B16F10 melanoma cells. ${ }^{*} p<0.05$. The expression of tyrosinase mRNA and protein were decreased by 23.24 and $48.13 \%$, respectively, following treatment with $A$. muricata $L$. extracts 

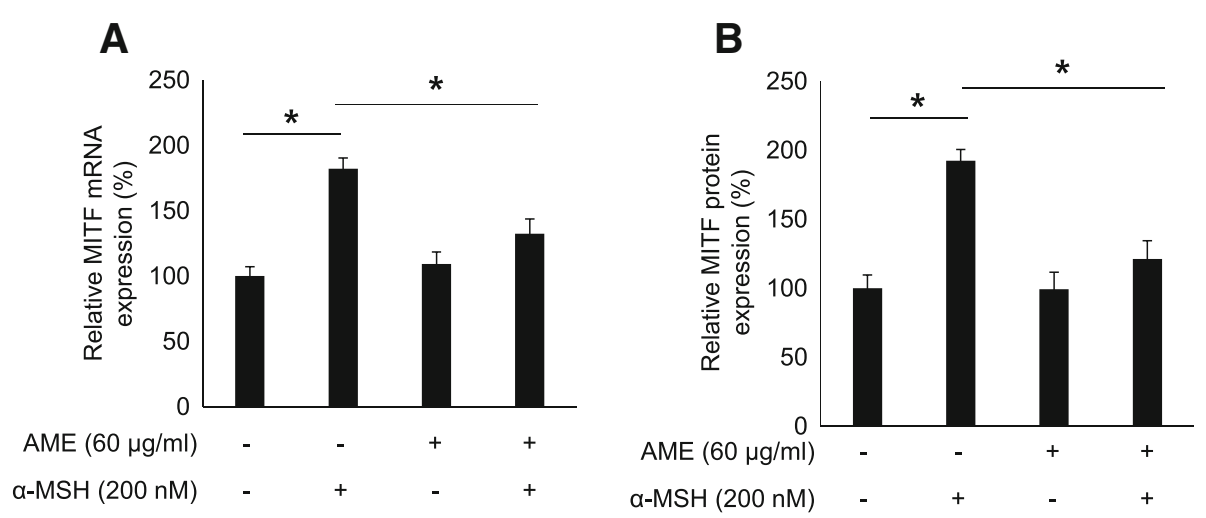

Fig. 4 Effects of A. muricata L. extracts on MITF expression in B16F10 melanoma cell. a Effects of A. muricata L. extracts on MITF mRNA and $\mathbf{b}$ protein expression in B16F10 melanoma cells. ${ }^{*} p<0.05$. To confirm the mechanisms by which $A$. muricata $\mathrm{L}$. extracts inhibit melanogenesis, we determined MITF mRNA and protein expression levels using qRT-PCR and Western blotting analyses, respectively. These experiments demonstrated that treatments with A. muricata L. lead to decreased expression of MITF

the effects of the present extracts on tyrosinase activities are transcriptional.

\section{Changes in MITF transcription and protein expression in the presence of $A$. muricata $\mathrm{L}$. extracts}

To confirm the mechanisms by which A. muricata L. extracts inhibit melanogenesis, we determined MITF mRNA and protein expression levels using qRT-PCR and Western blotting analyses, respectively. These experiments demonstrated that treatments with A. muricata L. lead to decreased expression of MITF, likely leading to decreased transcriptional activation of tyrosinase (Fig. 4).

\section{Discussion}

During in vivo melanogenesis, tyrosinase performs the rate-limiting step in the production of melanin by hydroxylating tyrosine to L-DOPA and then L-DOPA quinone (Saha et al. 2006). Melanin is subsequently synthesized by polymerization of amino acids and proteins (Maeda and Fukuda 1996). In the present MTT assays, $A$. muricata L. extracts had weak cytotoxicity in B16F10 cells when added at $120 \mu \mathrm{g} / \mathrm{mL}$ and no detectable cytotoxicity at $60 \mu \mathrm{g} / \mathrm{mL}$ (Fig. 1a). As shown in Fig. 1b, melanin contents in B16F10 cells were decreased in an extract concentrationdependent manner to $24.46 \%$ of that in the $\alpha$-MSH-treated control group.

In subsequent investigations of the mechanisms behind the effects of $A$. muricata L. extracts on melanogenesis, we showed that decreased tyrosinase activities reflected decreased tyrosinase mRNA and protein expression (Fig. 2), and these effects were concentration dependent. In agreement, we showed that the expression of the major tyrosinase, TRP-1 and TRP-2 transcription factor MITF (Battaini et al. 2000; Chun et al. 2002; Curto et al. 1999), was decreased in the presence of $A$. muricata L. extracts. Collectively, the present data indicate the potential of $A$. muricata L. extracts as a skin-whitening ingredient for functional cosmetics.

\section{Conclusions}

Herein, we investigated the effects of A. muricata L. extracts on melanogenesis and elucidated the ensuing mechanisms. Our experiments showed that treatment with A. muricata L. extracts decreases melanogenesis in a concentration-dependent manner by inhibiting the expression of intracellular tyrosinase and MITF. In detail, it has been demonstrated that $60 \mu \mathrm{g} / \mathrm{mL}$ of $A$. muricata L. extracts reduced $\alpha-\mathrm{MSH}$-inducing melanin contents, via diminishing mRNA and protein levels of tyrosinase and MITF in B16F10 melanoma cells, in vitro. Additional in vitro and in vivo studies will be necessary to identify the signalling pathways involved in A. muricata $\mathrm{L}$. extract-mediated molecular mechanisms, but these preliminary results suggest that $A$. muricata $\mathrm{L}$. extracts regulate MITF expression and can be used as a functional skin-whitening material that inhibits melanogenesis via direct transcriptional effects.

\section{Abbreviations}

A. muricata: Annona muricata; CAMP: Cyclic adenosine monophosphate; CREB: CAMP response element binding protein; DMEM: Dulbecco's modified Eagle's medium; DOPA: 3,4-dihydroxyphenylalanine; MITF: Microphthalmiaassociated transcription factor; MTT: 3-[4,5-dimethylthiazol-2-yl]-2,5diphenyltetrazolium bromide; PBS: Phosphate-buffered saline; PKA: Protein kinase A; SDS: Sodium dodecyl sulphate; TBST: Tris-buffered saline; TRP1: Tyrosinase-related protein 1

\section{Funding}

This work was supported by a grant from the Ministry of Trade, Industry and Energy (MOTIE), Korea Institute for Advancement of Technology (KIAT) through the Encouragement Program for The Industries of Economic Cooperation Region (Grant R0003962) and a grant from the Marine Biotechnology Program (20150184) funded by the Ministry of Oceans and Fishers, Republic of Korea and a grant from the Korean Health Technology R\&D Project (Grant No. HN13C0075), Ministry of Health \& Welfare, Republic of Korea. 


\section{Availability of data and materials}

Not applicable.

\section{Authors' contributions}

DJ, SJ, HKL, SHS, SJC and KK performed the experiments. KYK, JEK, SHJ and HJC were involved in the experimental design and advising. DJ, ISA and HJC analysed the data and wrote the manuscript. All authors have read and approved the final manuscript.

\section{Ethics approval and consent to participate}

Not applicable.

\section{Consent for publication}

Not applicable.

\section{Competing interests}

The authors declare that there are no competing interests.

\section{Publisher's Note}

Springer Nature remains neutral with regard to jurisdictional claims in published maps and institutional affiliations.

\section{Author details}

${ }^{1}$ Korea Institute of Dermatological Sciences, Cheongju-si,

Chungcheongbuk-do 28160, Republic of Korea. ${ }^{2}$ URG Inc., URG Building, Seochogu, Seoul 06753, Republic of Korea. ${ }^{3}$ Department of Cosmetology, Kyung-In Women's University, Incheon 21014, Republic of Korea.

${ }^{4}$ Department of Beauty Art, Faculty of Art, Suwon Women's University, Suwon-si, Gyeonggi-do 16632, Republic of Korea. ${ }^{5}$ Department of Skin Care and Beauty, Osan University, Osan-si, Gyeonggi-do 18119, Republic of Korea. ${ }^{6}$ Department of Skin Care and Cosmetics, Osan University, 45 Cheonghak-ro, Osan-si, Gyeonggi-do 18119, Republic of Korea.

Received: 19 May 2017 Accepted: 20 September 2017

Published online: 03 December 2017

\section{References}

Asare GA, Afriyie D, Ngala RA, Abutiate H, Doku D, Mahmood SA, et al. Antiproliferative activity of aqueous leaf extract of Annona muricata $\mathrm{L}$. on the prostate, BPH-1 cells, and some target genes. Integr Cancer Ther. 2015;14:65-74.

Baskar R, Rajeswari V, Kumar TS. In vitro antioxidant studies in leaves of Annona species. Indian J Exp Biol. 2007:45:480-5.

Battaini GE, Monzani L, Casella L, Santagostini R, Pagliarin R. Inhibition of the catecholase activity of biomimetic dinuclear copper complexes by kojic acid. J Biol Inorg Chem. 2000;5:262-8.

Busca R, Ballotti R. Cyclic AMP a key messenger in the regulation of skin pigmentation. Pigment Cell Res. 2000;13:60-9.

Chen JS, Wei C, Marxhall MR. Inhibition mechanism of koji acid on polyphenol oxidase. J Agr Food Chem. 1991;58:79-110.

Choi BW, Lee BH, Kang KJ, Lee ES, Lee NH. Screening of the tyrosinase inhibitors from marine algae and medicinal plants. Kor J Pharmacogn. 1998;29:237-43.

Chun HJ, Chli WH, Baek SH, Woo WH. Effect of quercetin on melanogenesis in melan-a melanocyte cells. Korean J Pharmacogn. 2002;33:245-51.

Curto EV, Kwong C, Hermersdorfer H, Glatt C, Santis V, Virador VJ, et al. Inhibitions of mammalian melanocytes tyrosinase: in vitro comparisons of alkyl esters of gentiic acid with other putative inhibitors. Biochem Pharmacol. 1999;57:663-72.

Hearing VJ, Tsukamoto K. Enzymatic control of pigmentation in mammals. FASEB J. 1991;5:2902-9.

Hosoi J, Abe T, Suda T, Kuroki T. Regulation of melanin synthesis of B16 mouse melanoma cells by 1 alpha, 25-dihydroxyvitamin D3 and retinoic acid. Cancer Res. 1985;45:1474-8.

Jeong MH, Kim SS, Kim JS, Lee HJ, Chio GP, Lee HY. Skin whitening and skin immune activities of different parts of Acer mono and Acer okamotoanum. Korean For Soc. 2005;99:470478.

Jimenez-Cervantes C, Solano F, Kobayashi T, Urabe K, Hearing VJ, Lezano JA, et al. A new enzymatic function in the melanogenic pathway. J Biol Chem. 1994; 269:17993-8000.

Kwon KJ, Bae S, Kim K, An IS, Ahn KJ, An S, et al. Asiaticoside, a component of Centella asiatica, inhibits melanogenesis in B16F10 mouse melanoma. Mol Med Rep. 2014;10:503-7.
Lans CA. Ethnomedicines used in trinidad and tobago for urinary problems and diabetes mellitus. J Ethnobiol Ethnomedicine. 2006;2:45-55.

Maeda K, Fukuda M. Arbutin: mechanism of its depigmenting action in human melanocyte culture. J Phamacol Exp Ther. 1996;276:765-9.

Mosmann T. Rapid colorimetric assay for cellular growth and survival: application to proliferation and cytotoxicity assays. J Immunol Meth. 1983;65:55-63.

Parvez S, Malik K, Ah KS, Kim HY. Probiotics and their fermented food products are beneficial for health. J Appl Microbiol. 2006;100:1171-85.

Saha B, Singh SK, Sarkar C, Bera R, Ratha J, Tobin DJ, et al. Activation of the Mitf promoter by lipid-stimulated activation of p38-stress signalling to CREB. Pigment Cell Res. 2006;29:595-605.

Sassone CP. Coupling gene expression to CAMP signalling: role of CREB and CREM. Int J Biochem Cell B. 1998;30:27-38.

Urabe K, Aroca P, Tsukamoto K, Mascagna D, Paulumbo A, Prota G, et al. The inherent cytotoxicty of melanin precursors. Biochim Biophys Acta. 1994;1221: 272-8.

Yu YG, Jeong MS, Choe JY, Kim JY. A study on whitening effect of Ephedra sinica extracts. Korean J Design Cult Soc. 2005;31:153-9.

\section{Submit your next manuscript to BioMed Central and we will help you at every step:}

- We accept pre-submission inquiries

- Our selector tool helps you to find the most relevant journal

- We provide round the clock customer support

- Convenient online submission

- Thorough peer review

- Inclusion in PubMed and all major indexing services

- Maximum visibility for your research

Submit your manuscript at www.biomedcentral.com/submit
) Biomed Central 